\title{
KARCINOM PARATIROIDNE ŽLEZDE
}

\section{AUTORI}

Odalović Božidar ${ }^{1,2}$, Jovanović Milan ${ }^{2}$, Zorić Goran², Mitić Javorka ${ }^{3}$, Tabaković Dejan ${ }^{1}$, Pajović Slavica ${ }^{1}$, Novaković Tatjana ${ }^{1}$

${ }^{1}$ Medicinski fakultet Priština - Kosovska Mitrovica

${ }^{2}$ Klinički Centar Srbije - Centar za Endokrinu Hirurgiju

${ }^{3}$ KBC Priština - Gračanica

\section{KORESPONDENT}

BOŽIDAR ODALOVIĆ

Medicinski fakultet Priština, Kosovska Mitrovica, Srbija

$\square$ odalovicb@gmail.com

\section{SAŽETAK}

Paratiroidne žlezde su male endokrine žlezde u vratu čoveka koje sekretuju paratiroidni hormon ili parathormon (PTH) koji zajedno sa kalcitoninom i D-vitaminom ima primarnu ulogu u regulaciji koncentracije kalcijuma i fosfata $u$ organizmu [1]. Najčešće oboljenje paratiroidnih žlezdi predstavlja povećano i nekontrolisano lučenje PTH koje se može definisati kao primarni hiperparatiroidizam, ako nastaje kao posledica pojačane funkcije jedne ili više paratiroidnih žlezdi ili kao sekundarni hiperparatiroidizam koji se javlja najčešće u hroničnoj bubrežnoj insuficijenciji ili kao posledica deficita vitamina D [2]. U našem prikazu slučaja smo opisali pacijenta sa karcinomom paratioidnih žlezdi koje je veoma retko oboljenje i predstavlja najređi maligni endokrini tumor.

Ključne reči: parotidna žlezda, karcinom, hirurški tretman

\section{UVOD}

Karcinom kao uzrok hiperparatiroidizma je veoma redak $i$ nađen je kod 0,5 - $2 \%$ operisanih od primarnog HPT. Veoma se često i makroskopski može prepoznati gde se karakteriše sivkastom prebojenošću, debelom kapsulom, tvrdom konzistencijom i infiltrativnim rastom u okolno tkivo, a često i uvećanim regionalnim limfnim čvorovima [3].

Karcinomi paratiroidnih žlezdi se javljaju sa približnom učestalošću kod oba pola i uglavnom u petoj $i$ šestoj deceniji života, mada se mogu javiti u svim uzrastima. Od dijagnostičkih procedura najčešće se radi ultrasonografski pregled i scintigrafija, a po potrebi i CT ili NMR.

Primarni vid lečenja karcinoma paratiroidnih žlezdi je hirurško lečenje, kome treba posvetiti maksimalnu pažnju, jer su svi drugi načini lečenja neuspešni.

Karcinom paratiroidnih žlezdi spada među neoplazme srednjeg stepena malignosti, a kod većine bolesnika neposredni uzrok smrti je hiperkalcemija a ne maligna priroda tumora [4].

\section{PRIKAZ SLUČAJA}

U ambulanti Endokrine hirurgije, Kliničkog Centra Srbije, po uputu lekara iz Doma Zdravlja, pregledan je pacijent Ž.B. rođen 1953. godine sa povećanim vrednostima ukupnog kalcijuma u $\mathrm{krvi} 3,27 \mathrm{mmol} / \mathrm{L}$, bolovima u ekstremitetima i gubitkom mišićne mase, što se naročito primećuje na nadlakticama (slika 1), anamnestičkom podatku o prisutnosti nefrolitijaze $i$ čestim bolovima u epigastrijumu, kao i nižim vrednostima krvne slike (HG-95, Er- 3,01). Palpacijom se nalazi tumefakcija na vratu.

$\mathrm{Na}$ osnovu kliničkih manifestacija posumnjalo se na postojanje oboljenja paratiroidnih žlezdi te je naloženo pacijentu da uradi ultrazvučni i scintigrafski (MIBI) pregled vrata, laboratorijske analize parathormona, kalcijuma i fosfata, RTG pluća, obe nadlaktice, šake i UZ abdomena.

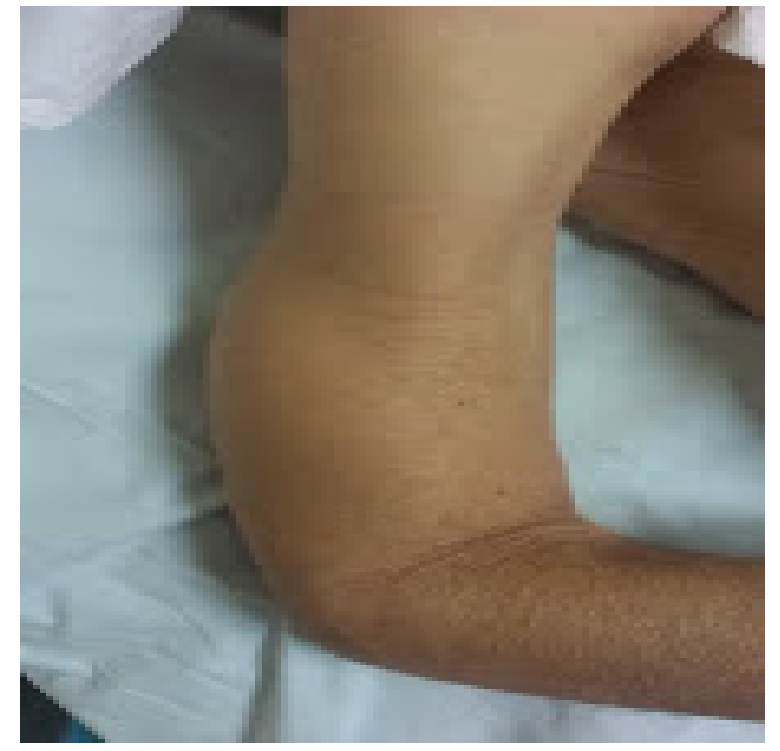

Slika 1. Deformitet nadlaktice 
$\mathrm{Na}$ zakazani kontrolni pregled pacijent donosi tražene rezultate, na osnovu kojih je jasno uočljivo da postoji oboljenje paratiroidnih žlezdi. Laboratorijske vrednosti ukazuju na kalcemiju 3,31 mmol/l, hipofosfatemiju $0,7 \mathrm{mmol} / \mathrm{l}$ i visoke vrednosti PTH $740 \mathrm{pg} / \mathrm{mL}$. $\mathrm{Na}$ rentgenskim snimcima je uočljiva demineralizacija kostiju šake i humerusa (slika 2 i 3).

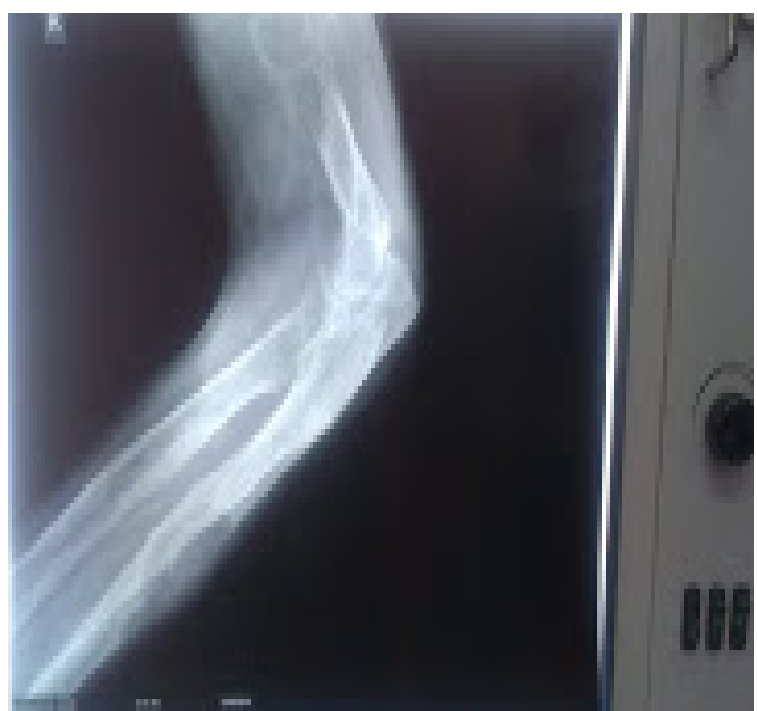

Slika 2. Demineralizacija humerusa

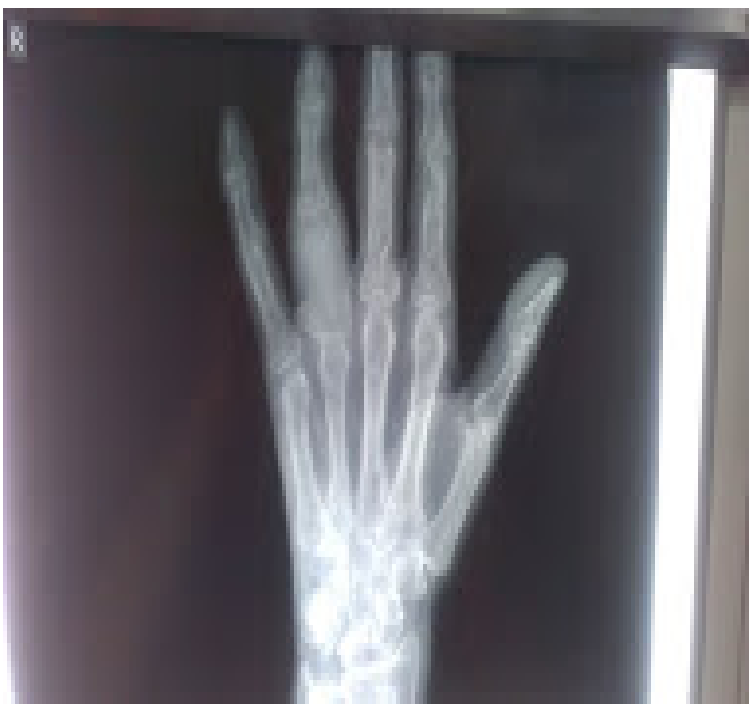

Slika 3. Demineralizacija falangi kostiju šake

Mibi scintigrafija: u loži desnog režnja tiroidne žlezde, kaudalno od samog režnja, dva nejednaka ovalna polja intezivne akumulacije, kaudalno veće.

Ultrazvuk: tioridna žlezda uredne veličine, desni lobus potisnut naviše izmenjenom paratiroidnom žlezdom heteroehogene strukture $6 \times 3 \times 3 \mathrm{~cm}$.

$\mathrm{Na}$ osnovu kliničkog pregleda, laboratorijskih rezultata i rezultata lokalizacione dijagnostike postavljena je indikacija za operativnim tretmanom, koji se nakon opšte preoperativne pripreme u uslovima OET anestezije $i$ učini. Koherovim rezom na bazi vrata, razdvajanjem pothioidne muskulature, duž bele linije pristupljeno viscelarnoj loži vrata. Identifikovana uvećana gornja-desna paratiroidna žlezda, čvrste konzistencije, $6 \mathrm{~cm}$ u promeru.(slika 4 i 5) $U$ jednom delu nejasno ograničena prema desnom lobusu tiroidne žlezde. Učinjena gornjedesna paratiroidektomija i desna tiroidektomija. Na preseku u donjem delu promene pratiroideje nodus čvrste, slaninaste konzistencije, $3 \mathrm{~cm}$. ( slika 6). Kontrola hemostaze,drenaža i rekonstrukcija rane po anatomskim slojevima.

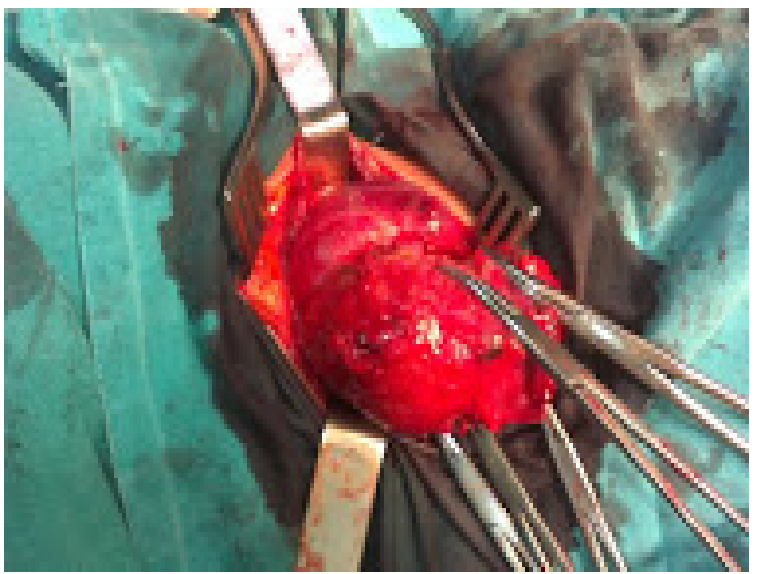

Slika 4. Intraoperativno uvećana paratiroidna žlezda

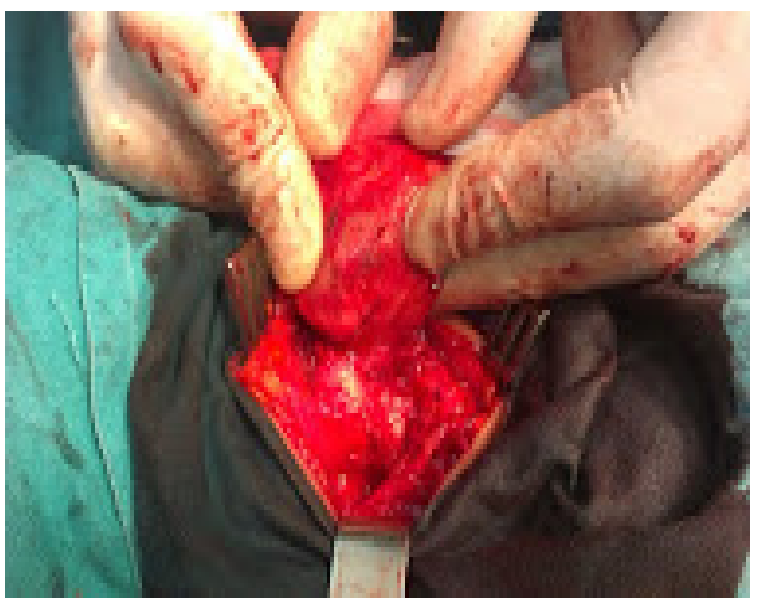

Slika 5. Intraoperativno uvećana paratiroidna žlezda

PH nalaz: Uz štitastu žlezdu se uočava deo paratiroidee. $U$ jednom fokusu se uočava raslojavanje kapsule tumorskim ćelijama ka štitastoj žlezdi. Uočava se tumor paratiroidne žlezde, sačinjen od glavnih ćelija u najvećem delu uniformnog izgleda, a manjim delom od izraženo pleomorfnih ćelija koje imaju džinovska hiperhromatična jedra. U tumoru se uočava hemoragična pseudocista u okvirima čijeg zida su hemosiderofagi, penušavi makrofagi holesterolski kristali, kao i limfocitni agregati. Prisutno raslojavanje kapsule, invazija vaskularnog prostora (CD34+endotelne ćelije), kao i fokalno postojanje debelih vezivnih pregrada unutar tumora.

$\mathrm{U}$ postoperativnom periodu vršena je kontrola kalcemije, fosfatemije i nivoa PTH u krvi. Na otpustu, pacijent u dobrom opštem i lokalnom stanju, sa vrednostima kalcemije $2,01 \mathrm{mmol} / \mathrm{l}$, te je otpušten uz odgovarajuću supstituciju kalcijumom i aktivnim metabolitima vitamina D. Vredenosti PTH $38 \mathrm{pg} / \mathrm{mL}$. 


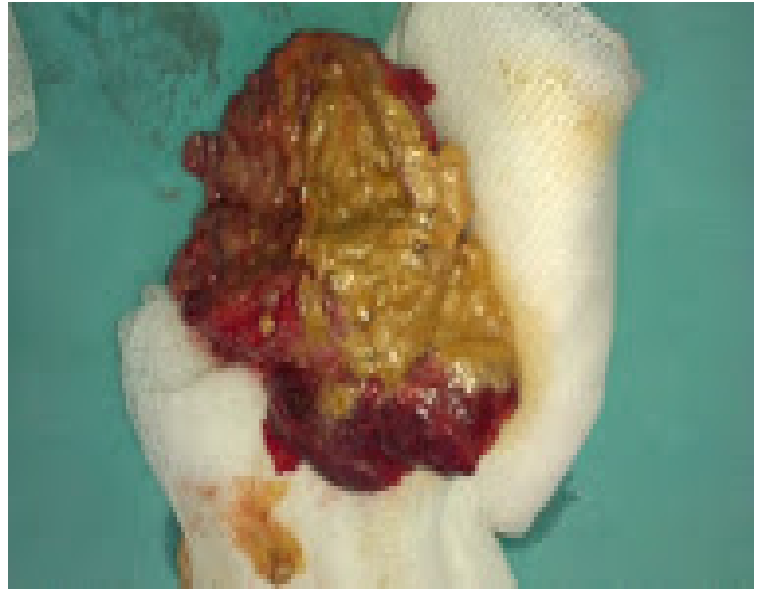

Slika 6. Presek paratiroidne žlezde poparatirodizam se javio kod 3,4\% bolesnika u Uppsala seriji, dok kod $91 \%$ bolesnika u istoj seriji nije bilo recidiva. Postoperativni mortalitet po Goteborg seriji u prvoj godini nakon operacije iznosi 1,56\%. U svim studijama utvrđen je porast mortaliteta od kardiovaskularnih bolesti.(7)

\section{ZAKLJUČAK}

Zbog male učestalosti karcinomi paratiroidnih žlezdi su nedovoljno poznati i proučeni maligni tumori za čije lečenje i praćenje nema jasno definisanih opšte prihvaćenih vodiča. Mogu biti hormonski aktivni i neaktivni, čija dijagnoza nije jednostavna, a vrlo česti i nepouzdana. Osnovni vid lečenja je operativni tretman.

\section{DISKUSIJA}

Karcinom paratiroidnih žlezdi je veoma retka pojava, te je ovaj maligni tumor danas gotovo pravi raritet, u strukturi obolelih od svih malignih tumora učestvuju sa svega $0,003 \%$. Zbog male učestalosti i dalje su nedovoljno poznati i proučeni maligni tumori te zbog toga nema jasno definisanih i opšte prihvaćenih vodiča za njihovo lečenje i praćenje. U studiji Sandelinija i saradnika u seriji pacijenata operisanih od primarnog hiperparatiroidizma -1650 , bilo je samo 6 pacijenata sa karcinom paratiroidnih žlezdi (0,3\%), dok su Wang I Gaz u svojoj seriji od 1200 pacijenata sa pHPT, pacijenata sa karcinomom bilo $28(2,3 \%)$.

Još je davne 1925. godine bečki hirurg Felix Mandl uradio prvu operaciju tumora paratiroidnih žlezdi. Od tada su se značajno promenili stavovi i principi lečenja ovog retkog oboljenja. Zahvaljujući lako dostupnom laboratorijskom testu merenja kalcijuma u serumu, javlja se sve veći broj bolesnika od primarnog hiperparatiroidizma. $(5,6)$

Klinička slika kod karcinoma paratiroidne žlezde je veoma varijabilna i zavisi, pre svega od toga da li je tumor funkcionalan (kalkuloza bubrega, promene na kostima, ulkus želuca, hiperkalcemijska kriza) ili afunkcionalan (disfonija, dispneja, disfagija).

Hirurške komplikacije se kreću od lezije n. reccurensa do hipoparatiroidizma. Postoperativni hi-

\section{LITERATURA}

1. Rodgers SE, Perrier ND. Parathyroid carcinoma. Curr Opin Oncol 2006, 18: 16-22.

2. Paul RG, Elston MS, Gill AJ, Conaglen JV, Meyer-Rochow GY. Hipercalcaemia due to parathyroid carcinoma presenting in the third trimester of pregnancy. Aust N Z J Obstet Gynaecol 2012, 52: 204-207.

3. Živaljević V. Hirurgija paratiroidnih žlezdi. Medicinski fakultet Beograd 2015, 9: 193-220.

4. Pelizzo MR, Pioto A, Bergamasco A, Rubello D, Casara D. parathyroid carcinoma. Therapeutic strategies derived from 20 years of experience. Minerva Endocrinol 2001, 26:23-29.

5. Shane E. Parathyroid carcinoma. J Clin Endocrinol Metab 2001, 86: 485-493.

6. Filipović A, Paunović I, Savjak D, Živković T. Parathyroid carcinoma. Vojnosanit Pregl 2006, 63: 765-769.

7. Sillero Sanchez A, Atienza Iglesias MA. Diagnostic-therapeutic management of parathyroid carcinoma. An Med Interna 2002, 19:644-648. 


\section{ENGLISH}

\section{CANCER OF THE PARATHYROID GLANDS}

Odalović Božidar ${ }^{1,2}$, Jovanović Milan ${ }^{2}$, Zorić Goran ${ }^{2}$, Mitić Javorka ${ }^{3}$, Tabaković Dejan ${ }^{1}$, Pajović Slavica ${ }^{1}$, Novaković Tatjana ${ }^{1}$ ${ }^{1}$ Medical Faculty Priština - Kosovska Mitrovica

${ }^{2}$ Clinacal Center Serbia - Center for Endocrine Surgery

${ }^{3}$ CHC Priština - Gračanica

\section{SUMMARY}

Parathyroid glands are small endocrine gland in the neck that men secrete parathyroid hormone, or PTH ( PTH), which together with calcitonin and vitamin - D has a primary role in regulating the concentration of calcium and phosphate in the body. The most common disease of the parathyroid gland presents increased and uncontrolled secretion of PTH, which can be defined as primary hyperparathyroidism, if occurs as a result of enhanced functions of one or more of the parathyroid glands, or secondary hyperparathyroidism, which occurs most often in chronic renal failure or as a result of the deficiency of vitamin D. In our case report we describe a patient with cancer paratioidnih gland, which is a very rare disease and is the rarest malignant endocrine tumor.

Key words: parotid gland, carcinoma, surgical treatment 